\title{
Clinical Assessment of Tissue Healing of Extracted Sockets Irradiated with 940 Nm Diode Laser
}

\author{
A. S. Mahmood \\ Assist. Professor at the Institute of Laser for Postgraduate Studies/ University of Baghdad \\ N. H. Hammoodi \\ ,B.D. S, Msc student at the Institute of Laser for Postgraduate Studies/ University of Baghdad
}

\begin{abstract}
Background: Dental extraction is a surgical procedure that requires hemostasis, several haemostatic agents may be beneficial, laser-assisted coagulation can be used for many surgical procedures like dental extraction.

Objective: The objective of this study was to evaluate the role of $940 \mathrm{~nm}$ diode laser-assisted coagulation following dental extraction in the soft tissue healing of the extraction wound site.

Methods: Thirty patients with 32 extraction sites were randomly separated into two groups. Group A patients with 17 extraction sites, their bleeding sites were stopped by exposing them to a $940 \mathrm{~nm}$ diode laser operated in a continuous wave mode of radiation and $0.1193 \mathrm{~W} / \mathrm{mm}^{2}$ power density, while group B patients with 15 extraction sites, the healing of the extraction sites left to happen normally.

Results: Group A extraction sites presented with less pain and accelerated healing compared with group B extraction sites.

Conclusion: The use of $940 \mathrm{~nm}$ diode laser operated in $\mathrm{CW}$ mode with $0.1193 \mathrm{~W} / \mathrm{mm}^{2}$ power density on immediate extraction socket site causes an immediate hemostasis and accelerated wound healing.

Practical Applications: The immediate hemostasis and healing acceleration achieved with laser radiation can be of very beneficial for immediate fixed restorations.
\end{abstract}

KEYWORDS

socket healing, $940 \mathrm{~nm}$ diode laser, dental extraction.

CITE THIS ARTCLE

Mahmood A,Hammoodi N. Clinical Assessment of Tissue Healing of Extracted Sockets Irradiated with 940 Nm Diode Laser. Iraqi Dent. J. 2015; 37(3):124-128. http://www.iraqidentaljournal.com

$$
\begin{aligned}
& \text { التقييم السريري لشفاء انسجة المقابس السنية المنزوعة المشععة بليزر الدايود } 940 \text { نانومتر }
\end{aligned}
$$

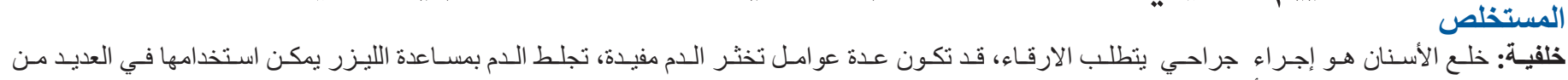

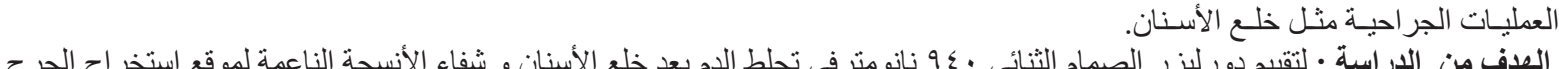

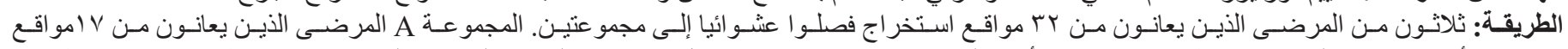

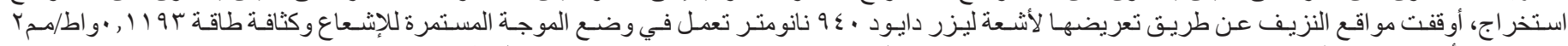

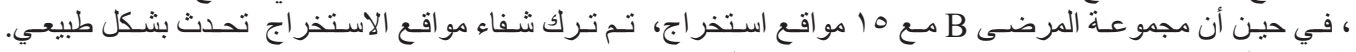

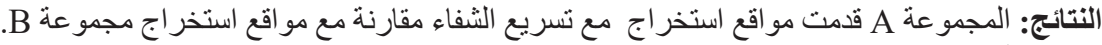

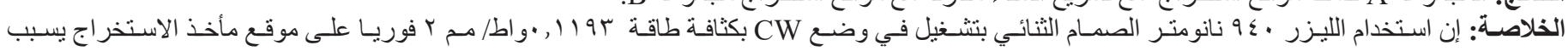

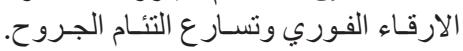

\section{INTRODUCTION}

After tooth extraction, one wall or more of the socket can be partially or totally missing or present fissures due to previous tooth trauma, traumatic extraction, deep periodontal pocket or previous apical surgery. The socket is considered intact or 4-walled, when the socket is surrounded by bone with the absence of fissures, dehiscence and fenestration ${ }^{(1)}$. Early studies have shown that during the process of healing of the extraction socket the following events occur: firstly, a blood clot (mainly blood cells and network of fibrin) forms and fills the empty socket. Then, the blood clot matures and is organized by the formation of granulation tissue (rich in newly formed vascular structure, abundance of inflammatory cells such as neutrophils, macrophages and lymphocytes and fibroblasts infiltrate). The granulation tissue arises two to three days after tooth extraction and replaces the blood clot completely by the seventh day ${ }^{(2,3)}$. Thereafter, a gradual replacement of the granulation tissue by provisional connective tissue takes place. This provisional connective tissue is made up of densely packed mesenchymal cells, osteoblasts (cells produce bone), collagen fibers and vessels. In the next stage, formation of osteoid (non-mineralized bone matrix) by the osteoblasts begins and gradually converts to new mineralized bone filling of the socket from the base and periphery of the socket. An epithelialization of the wound surface occurs parallel with the reparative processes in the socket ${ }^{(2,3)}$. Quantitative analysis of the tissue has not been performed so that the 
amount of new bone formation could not be evaluated. Furthermore, most of the studies cited above were of comparatively short duration and, thus, have no information related to the later phase of socket healing including the process of remodeling of newly formed bone tissue and connective tissue (4)

In recent studies using a canine model, the process of healing in mandibular extraction sockets during 6-month interval shows that within the first 4 weeks there is an initial phase of progressive bone formation so that the socket is mainly dominated by newly formed bone by the 30th day. After that, the onset of resorption and remodeling of this newly formed bone begins and gradual placement of bone marrow occurs and by 6 months after tooth extraction, mineralized bone occupies only $15 \%$ of the extraction socket ${ }^{(4)}$. Since the extraction wound healing and bone regeneration is slower in humans than in $\operatorname{dogs}^{(5)}$, there will be some variation of the rate of bone formation and remodeling between humans and dogs at certain periods. Little is known about the peak of the initial phase of bone formation and the time in which bone turnover in human begins. Such information could be of great value to determine the ideal time of implant placement after tooth extraction $(4,5)$.

Diode lasers for dentistry operate in the near infrared region. The most commonly used wavelengths are 810, 940 and $980 \mathrm{~nm}$, because these wavelengths are very well absorbed by pigmented tissues, haemoglobine and melanin, which makes the diodes suitable for soft tissue surgery, endodontics, periodontics and low level laser treatment (LLLT) (6). Diode lasers are bactericidal ${ }^{(7,8)}$ and aid in coagulation. By using mechanical shutters the cwmode of the diode was changed into a chopped mode, the dose was reduced, but the peak powers of the pulses equaled the peak powers of the $\mathrm{CW}$ - mode ${ }^{(9)}$.

The kind of tissue and the wavelength are essential for absorption. There are some more factors involved in laser-tissue interactions as the frequency, the dose applied, the pulse duration, power density and very important: the mode of operation $(\mathrm{CW}$, pulsed, super pulsed). Depending on the mentioned factors, there are different effects to be watched in the tissue ${ }^{(10)}$. In oral surgery, diodes are used because of several advantages; efficient cutting, good haemostasis, nearly without bleeding and therefore good visibility of the op site, mostly no sutures needed, no or only small post op. oedema, bactericidal effect, pain reduction post and intra op. treatment, no secondary bleeding, precision of cut, calculated depth of cut, reduced application of drugs (antibiotics, analgesics ), only minimal destruction of adjacent tissues, uncomplicated handling, high patient acceptance, low level of scar forming, use on patients with haemorrhagic diathesis without or only with little substitution, good handling due to fiberoptics, reduction of needed instruments (change of parameters- different effects), treatment duration shorter ( no suture, not often change of instrument..), biostimulation of the surrounding tissue ${ }^{(10,11,14)}$. Diode laser wavelength is very well absorbed in pigment, melanin and most importantly for hemostasis by the hemoglobin molecule ${ }^{(13)}$.

\section{METHODS}

According to the previous studies, laser dose parameters as power density and exposure time were deduced out of a pilot study to coagulate rabbit blood in Dirham tubes using $980 \mathrm{~nm}$ diode laser in (CW) mode ${ }^{(15,16)}$, which was incident on human blood treated with EDTA in Durham tubes

The human blood absorbance was recorded by a spectrophotometer in which the absorbance of human blood was recorded at $940 \mathrm{~nm}$ wavelength , by introducing of the human blood sample treated with EDTA into the spectrophotometer and the wavelength $940 \mathrm{~nm}$ was selected.

The patients attended for removal of teeth because of extensive caries or root fracture. Patients with active periodontal lesions or advanced periodontal disease comprising severe tooth mobility with deep pockets, chronic periodontal abscess were included in this study. The following groups of patients were excluded from the study: patients who were taking antibiotics for an existing infection, those with underlying medical conditions such as diabetes mellitus, severe nutritional deficiencies, endocrine disturbances; those with social habits such as cigarette smoking and alcohol consumption; patients on oral contraceptives and steroid therapy; and those with a history of radiotherapy for the treatment of head and neck malignancies.

The 30 patients (with 32 extraction sites) were randomly divided into groups: Group A patients of 17 extraction sites and Group B patients of 15 extraction sites. The bleeding in Group A was stopped by exposing the patients to $940 \mathrm{~nm}$ diode laser radiation operated with $0.1193 \mathrm{~W} / \mathrm{mm}^{2}$ power density for enhancing the healing process. The bleading of extracted socket sites in Group B was left to coagulated normally without radiation intervention. The extraction procedure was performed under local anesthesia without the elevation 
of a mucoperiosteal flap; therefore, no primary wound closure was performed. Meticulous care was taken to avoid surgical trauma of the surrounding tissue by using a periotome and the appropriate dental forceps. A thorough curettage of all soft tissue debris in the alveolus was performed using a periapical curette to ensure the removal of all granulation tissue and periodontal ligament to stimulate bleeding from the osseous base.

Gentle squeezing of extracted sockets was done for Group B patients, whom exposed to radiation for coagulating the blood and enhancing the healing process. They were instructed to bite on a piece of gauze and exert a pressure on their sockets for fortyfive minutes, and not to rinse their mouths for 24 hours. Analgesics and antibiotics were prescribed and appointment was gaved to them for follow up.

Squeezing of the extraction sockets was not done for Group A patients and when multiple extraction was indicated the interproximal areas was not sutured, other instructions were the same for both groups. The application of diode laser had some difficulty because the the laser tip was rigid and long. There was restriction in the movement of the laser tip especially in the posterior sites; therefore, the application was in defocus mode by a distance of $5 \mathrm{~mm}$ away from the socket surface and with some angulations.

Application of diode laser was without optical fiber tip initiation and defocused mode in a perpendicular direction to the socket, beginning from the central portion of the blood in the socket in a circular slow motion toward the borders of the socket. When blood clot had completely closed the extraction wound surface, patients were instructed to exert a pressure by a piece of cotton on the extraction site for half an hour. No antibiotics but paracetamol analgesic taken on need were prescribed to patients and an appointment was given to them for follow up.

All patients were examined at 3 days, $1^{\text {st }}, 2$ nd and $3^{\text {rd }}$ week after surgery to assess pain, edema, infection, functional complications (speaking, eating, and brushing) and extraction wound healing progress.

In the follow up appointments, we did clinical observations and assessments during examination, in addition to the data collected from the questionnaire sheets including the patient's notes on the operation day and the first week postoperatively.

Extraction wound healing was assessed by clinical examination depending on inspection and palpation of the extraction site during the follow up appointments.

\section{RESULTS}

The human blood absorbance was recorded by a spectrophotometer in which the absorbance of human blood was recorded at $940 \mathrm{~nm}$ wavelength. The reading was (1.999 which indicate the absorbance of human blood at $940 \mathrm{~nm}$ laser radiation) that equal to (the ratio of incident intensity to the absorbed intensity) Figure (1).

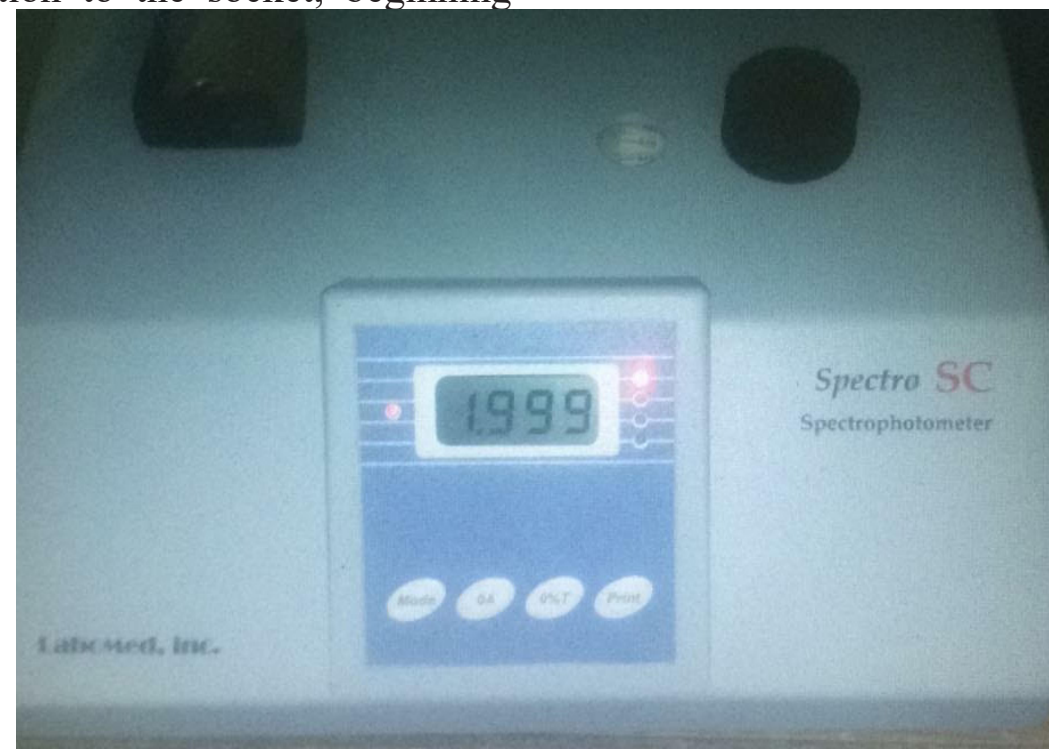

Figure (3.1) Blood absorbance of treated with EDTA (anticoagulant material) at $940 \mathrm{~nm}$ spectrophotometer recording.

The clinical observation of the wound site for the clinical assessment of the tissue healing was done by taking photographs to the extraction site. Photographs are taken before and after exposing to the laser irradiation and at follow up intervals at 3rd day postoperatively, 1st week, 2nd week and 3rd week post- operatively.

The clinical examination of the extraction sites immediately after laser irradiation had presented with an immediate hemostasis was obvious in all patients of the groups (A and B). The clinical examination of the extraction sites at 3 days, $1^{\text {st }}, 2^{\text {nd }}$ and $3^{\text {rd }}$ weeks 
after extraction was presented. The wound sites of group A healing are faster as compared with the wound sites of the group B patients, figure (2). That was an indication of laser acceleration of postextraction wound site healing. The post-extraction wound sites of the laser group that presented with (the healing acceleration appearance) appears with close approximation of the wound edges on each other and nearly closing of the wound sites at the 3rd day interval. This sign was not appear even after the 1st week interval of the group A wound sites and tend to appear in less closed approximation between the 2nd and 3rd week interval.

The clinical signs of infection are absent in laser group, while present at the 3rd day interval in 2 cases of group B, these signs are of alveolar ostietis, which are severe pain, halitosis, empty sockets and delay of the healing in the extraction wound site. the absence of these signs in the laser group indicate its antiseptic properties of the laser light.

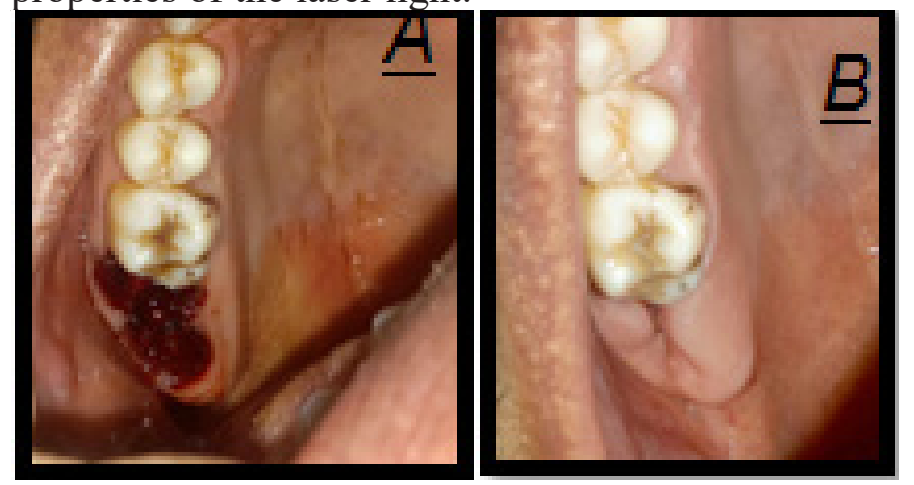

Figure (2) A. Immediate post extraction maxillary $2^{\text {nd }}$ and $3^{\text {rd }}$ molars sites without suturing that exposed to laser radiation for the purpose of coagulation. B. The healing site at the $7^{\text {th }}$ day appointment, note the close approximation of the wound site edges.

\section{DISCUSSION}

The acceleration of the wound healing agreed with Mirdan who found in histopathological section of the tooth socket for a rabbit (15 sec exposure time) at the1st day showing the granulation tissue and the organization of hemorrhage site, on the third day mature bone appeared which was characterized by trabiculae, lacunae in addition to osteocytes; which were evident at the tenth day, all of which are indications of acceleration of wound healing (15).

The penetration depth of the radiation was (0.692) $\mathrm{mm}$, which was measured from the absorbance value (1.999) that equal to (the ratio of incident intensity to the absorbed intensity) and the Absorbance $\mathrm{A}$ is equal to - $\log$ the Transmittance $\mathrm{T}$ which in turn is equal to the (ratio between incident to transmitted intensities) and from an equation:

$\mathrm{T}=10^{-\mathrm{A}}$ (Beer- Lambert Law);
$\mathrm{A}=-\log \mathrm{T}$

optical depth $=\ln _{10} \mathrm{~A}^{(17,18)}$. From the previous measurement, that's mean $(0.692 \mathrm{~mm})$ of blood was coagulated because clotting is due to apsorption (Vuylsteke, 2009; Mirdan, 2012), the underlying areas of blood filled the socket beneath the absorption depth, there is layers of blood exposed to scattered laser light, which cause biostimulation effect that cause the extraction wound healing acceleration, this finding was agreed with ${ }^{(15,19)}$ who used $980 \mathrm{~nm}$ diode laser in $0.86 \mathrm{~W}$ for the purpose of extraction wound site coagulation of a rabbit tooth socket. Vuylsteke and Mirdan stated that: 'Due to fluctuations in the refractive index of these media (blood during the coagulation process), the propagation of light into the tissue is modified and the scattering affects where the absorption will occur. The scattering usually reduce the penetration of light into the tissue. Heating decreases with tissue depth, as absorption and scattering attenuate the incident beam. At $940 \mathrm{~nm}$ $980 \mathrm{~nm}$ wavelengths, scattering coefficient is 0.6 $0.64 \mathrm{~mm}^{-1}$ and absorption coefficient $0.25-0.28 \mathrm{~mm}^{-1}$ in blood gives out an optical extinction coefficient of $0.82-0.86 \mathrm{~mm}^{-1}{ }^{(19)}$. Those numbers prove that clotting was achieved due to absorption. Scattering was the factor that limits the laser photothermal effect to be conserved on the clot formation only but instead the socket healing may be stimulated by the remaining scattered light from the incident laser that approve the biostimulation of the laser radiation in acceleration of the extraction wound healing ${ }^{(15)}$.

\section{CONCLUSIONS}

Irradiation of bleeding sockets with $940 \mathrm{~nm}$ diode laser caused immediate clot formation and accelerate the healing of the extraction socket site. This procedure was safe, reliable, lessen the pain and the possibility of infection and showed no adverse effects.

\section{REFERENCES}

1. Newman M, Takai H, Klokkevold P, Carranza F. Carranza's clinical Periodontology. 10th ed. Philadelphia, USA: Elsevier Saunders Co; 2006. 1145.

2. Carlsson GE, Bergman B, Hedegard B. Changes in contour of the maxillary alveolar process under immediate dentures. A longitudinal clinical and $x$-ray cephalometric study covering 5 years. Acta Odontol Scand 1967 ; 25(1):45-75

3. Amler MH. The time sequence of tissue regeneration in human extraction wounds. Oral Surg Oral Med Oral Pathol 1969; 27:309-18

4. Cardaropoli G, Araújo M, Lindhe J. Dynamics of bone tissue formation in tooth extraction sites. An experimental study 
in dogs. J Clin Periodontol. 2003; 30:809-818.

5. Fickl S, Zuhr O, Wachtel H, Bolz W, Huerzeler M. Tissue alterations after tooth extraction with and without surgical trauma: a volumetric study in the beagle dog. J Clin Periodontol. 2008 ;35(4):356-63.

6. Adams TC, Pang PK: Lasers in aesthetic dentistry. Dent Clin North Am 2004;48: 833-860.

7. Robert A. Convissar, DDS, FAGD, Principles and Practice of Laser dentistry ;2010,ch $2: 12$ 26

8. Gutknecht N, et al.: Proceedings of the 1st International Workshop of Evidence Based Dentistry on Lasers in Dentistry. Quintessence Publishing Co.Ltd.; 2007.

9. Capodiferro S, Maiorano E, Loiudice AM, Scarpelli F, Favia G:Oral laser surgical pathology: a preliminary study on the clinical advantages of diode laser and on the histopathological features of specimens evaluated by conventional and confocal laser scanning microscopy Minerva Stomatol 2008;(1),57: 1-7

10. Coluzzi DJ, Convissar RA: Atlas of laser applications in dentistry, Hanover Park; , 2007, I 11 Quintessence.

11. Geldi C, Bozkulak O, Tabakoglu HO, Isci S, Kurt A, Gulsoy M: Development of a surgical diode-laser system: controlling the mode of operation. Photomed Laser Surg 2006;24(6): 723-729

12. Gouw- Soares S, Tanji E, Haypek P, Cardoso W, Eduardo $\mathrm{CP}$ : The use of Er:YAG, Nd:YAG, and Ga-Al-As-Lasers in Periapical Surgery: a three year clinical study. J Clin Lasers Med Surg 2001;19(4): 193-198.

13. Gulsoy M, Dereli Z, Tabakoglu HO, Bozkulak O: Closure of skin incisions by $980 \mathrm{~nm}$ diode laser welding. Lasers Med Sci 2006, 21(1): 5-10.

14. Stübinger S, Saldamli B, Jürgens P, Ghazal G, Zeilhofer HF: Soft tissue surgery with the diode laser- theoretical and clinical aspects. Schweiz Monatsschr Zahnmed 2006; 116(8): 812-820.

15. Mirdan B.M. , A 980nm Diode Laser Clot Formation of the Rabbit's Dental Sockets after Teeth Extraction. Iraqi J. Laser, Part B, 2012; (11): 37-42.

16. Mirdan M. B. , Laser induced clot formation in blood treated by EDTA, Natural Science, 2013; 5, (7): 796-799.

17. Niemz M. H. Laser-tissue interactions: fundamentals and applications, Springer, 2007; (3):1-100.

18. Nic M. Compendium of Chemical Terminology, the Gold book, Blackwell Scientific Publification. online corrected version :http://goldbook.iupac.org ; 2006(2).

19. Vuylsteke M, Van Dorpe J, Roelens J, et al., Endovenous laser treatment: a morphological study in an animal model.Phlebology; 2009; (24):16-75. 